\title{
Pornochanchada do avesso: 0 caso das mulheres monstruosas em filmes de horror da Boca do Lixo
}

\section{Laura Loguercio Cánepa}

\section{Resumo}

Este artigo discute uma série de pornochanchadas de horror realizadas no Brasil entre o final dos anos 1970 e o começo dos 1980 que foram protagonizadas por mulheres monstruosas e tiveram homens como suas vítimas principais, invertendo uma das estruturas básicas do filme erótico brasileiro, que consistia na representação dos homens sempre mais fortes e ameaçadores do que as mulheres. 0 objetivo é demonstrar que 0 cinema praticado nos estertores da pornochanchada trazia alguma discussão sobre a condição feminina no cinema e na sociedade, mostrando capacidade de reflexão e de auto-crítica que nem sempre é considerada na análise dessa cinematografia.

\section{Palavras-chave}

Sexploitation movies. Pornochanchada brasileira. Horror. Monstruosidade. Gênero feminino.

Laura Loguercio Cánepa | laura_canepa@yahoo.com.br Doutora em Multimeios pela Universidade Estadual de Campinas UNICAMP. Professora do Mestrado em Comunicação da Universidade Anhembi Morumbi - São Paulo.

\section{Introdução}

Apesar de observada apenas genericamente pelos estudos sobre o cinema brasileiro, uma das mais variadas e numerosas vertentes de nossa cinematografia popular está ligada ao segmento chamado "de exploração". Esse antigo filão da atividade cinematográfica adquiriu muitas faces ao longo do tempo e ao redor do planeta, mas, estrito senso, consiste na produção de filmes que têm como objetivo principal explorar temas considerados polêmicos ou tabus, usando seu potencial de escândalo com fins comerciais. 0 termo, adotado do inglês exploitation, foi derivado das práticas publicitárias e chamarizes usadas em cartazes, anúncios de jornais e trailers, para suprir, em produções baratas realizadas desde as primeiras décadas do século $\mathrm{XX}$, a falta de estrelas e astros famosos ou 0 reconhecimento como produtos de grandes estúdios. Após os anos 1950, exploitation também passou a designar um conjunto mais específico de filmes eróticos, policiais e de horror destinados a atrair principalmente 0 público masculino. 
Na dissertação de mestrado A cultura do lixo: horror, sexo e exploração no cinema, um dos poucos trabalhos acadêmicos de fôlego feitos sobre o exploitation no Brasil, Lúcio Piedade (2002), partindo das ideias do pesquisador estadunidense Eric Schaeffer ${ }^{1}$, divide a história do cinema de exploração em quatro fases. A primeira, a qual chama de Clássica, abrange filmes muito baratos, exibidos marginalmente entre os anos 1920 e 1950, cujos temas centrais eram assuntos proibidos como sexo, prostituição, uso de drogas, nudez e delinquência juvenil (às vezes feitos com fins educativos, mas que acabavam sendo apropriados pelo circuito de exploração). A segunda fase, a do Teenexploitation, envolve espetáculos feitos especificamente para jovens, tratando dos temas clássicos e também de novos tipos de histórias de horror estreladas por terríveis monstros, num fenômeno que deu grande impulso ao cinema B nos EUA. A terceira fase, tida como a da Explosão, a partir de 1959, marca o surgimento de vertentes e ramificações, fazendo com que a palavra exploitation passasse a designar gêneros muito específicos a partir de subdenominações como sexploitation (para filmes cujo chamariz principal é o apelo sexual), blaxploitation (para filmes com temática violenta envolvendo afrodescendentes), nunexplitation (para histórias bizarras passadas em conventos); woman in prison (para filmes sobre presídios femininos) etc. Por fim, na fase da Generalização, o cinema de exploração se espalha pelo mundo, tendo suas próprias versões nacionais e vendo muitas de suas práticas serem apropriadas pelo cinema mainstream (PIEDADE, 2002, p. 17-18).

Embora tenha tido alguns momentos importantes no período do cinema mudo brasileiro, quando os filmes criminais (semelhantes a outros produzidos no mundo inteiro) davam origem ao que poderia ter se tornado uma importante linhagem do cinema de exploração, essa indústria teve seu apogeu, no Brasil, na década de 1970, exatamente na fase que Piedade identifica como a da "generalização". A face mais característica desse fenômeno foi 0 cinema erótico da Boca do Lixo², em São Paulo, que repetia diversas estratégias do cinema de exploração, em particular do sexploitation, como os títulos sensacionalistas chamando a atenção para o conteúdo sexual, o baixo orçamento, a ligação das histórias aos clichês dos gêneros narrativo-ficcionais canônicos, o status cultural da proximidade com a principal estação de trem da cidade), e manteve sua vocação mesmo com a sua degradação a partir da década de 1950 (quando foi transformada em zona de meretrício e de tráfico de drogas), mas apenas a partir dos anos 1960 os filmes ali produzidos ganharam uma face própria baseada no conteúdo erótico que os fez ser conhecidos como "pornochanchadas paulistas". 0 sistema de produção desses filmes era compartilhado por várias produtoras e se caracterizava pela circulação de artistas em diferentes empresas e pela produção em parceria com os exibidores. 
duvidoso das produções, o consumo popular majoritariamente masculino, a distribuição em cinemas de segunda linha, e, conforme nos interessa particularmente neste artigo, a misoginia e a "objetificação" das mulheres, apresentadas quase sempre como alvos de um olhar invasivo e, não raro, sádico e brutal.

Essa configuração típica de uma indústria de sexploitation na Boca do Lixo deu origem a centenas de longas-metragens eróticos de ficção ligados a diferentes gêneros, como 0 faroeste, o policial e o horror. Este último, que sempre deu alegrias aos produtores de filmes de exploração pela facilidade com que dá margem ao sensacionalismo, seguia, na Boca, os padrões estéticos e narrativos lá consagrados - tendo, em geral, como vítimas do horror, as personagens femininas, de preferência jovens, apavoradas e com pouca roupa. Mas, como se deseja demonstrar e discutir neste artigo, alguns desses filmes trocavam a posição inferiorizada das mulheres e as colocavam não mais como vitimas, e sim como algozes no horror. Não por acaso, trata-se de alguns dos filmes eróticos mais interessantes realizados no Brasil naquele período, justamente pela autoconsciência e pela ironia que continham.

Retomando a lembrança desse período, 0 objetivo deste artigo será analisar brevemente esse conjunto de filmes protagonizados por mulheres monstruosas, levantando algumas hipóteses sobre um momento específico do sexploitation brasileiro, no qual os filmes davam mostras de querer problematizar, de maneira mais evidente, as questões referentes à condição feminina no cinema erótico e na sociedade.

\section{Sexploitation de horror brasileiro}

Como nos lembra Nuno César de Abreu (2006, p. 38), desde o começo da década de 1960, o cinema erótico entrava na pauta de público, realizadores e produtores, tanto na América quanto na Europa, refletindo, com enorme sucesso de bilheteria, um momento de intensas transformações comportamentais no campo da sexualidade. Nesse contexto, se uma parte da cinematografia mundial se dedicou ao tema do sexo em filmes artística e intelectualmente ambiciosos, o mesmo clima deu espaço para que a indústria do cinema de exploração passasse a testar os limites da exposição de cenas de sexo e de nudez (sobretudo) feminina, dando origem a diversos "ciclos" de filmes conhecidos como sexploitation movies, nos quais as figuras femininas eram, quase sempre, reduzidas a meros objetos sexuais: dos nudie-cuties (filmes relativamente ingênuos que exploravam a nudez de mulheres, e que foram bastante populares entre os anos 1950 e o começo dos anos 1960) passouse para os softcores (que tinham cenas de sexo simuladas) e, então, as mulheres passaram a ser também vítimas de toda sorte 
de maus-tratos ${ }^{3}$ nos roughies (histórias de estupros e assassinatos de mulheres), nos kinkies (filmes eróticos com temática de fetichista e sadomasoquista), nos filmes de "woman in prision" (que traziam histórias sórdidas passadas em presídios ou internatos femininos), nos ghoulies (histórias de horror envolvendo mulheres ameaçadas e violentadas por entidades sobrenaturais) e em outros subgêneros do sexploitaion.

0 processo começou nos EUA, mas rapidamente se alastrou pela Europa e Ásia, com extensa produção de filmes de sexploitation suecos, alemães, japoneses e italianos, que também se espalharam pelo mundo. A relação desses "modelos" do sexploitation com o cinema erótico brasileiro foi notória, mas um pouco tardia - começou no final dos anos 1960 - e raramente se reduziu à mera imitação. Tratava-se de produzir similares nacionais do produto importado (inicialmente, com base nas comédias eróticas italianas em episódios), absorvendo também elementos cinematográficos "nativos", como um certo tipo de comédia de costumes e de paródia. Tal relação entre comédia e erotismo ficaria conhecida como pornochanchada. Segundo Abreu,
[...] uma das bases ou fontes de inspiração temas, situações, tipos - na comédia erótica brasileira foram as comédias italianas, em geral compostas de três episódios com tramas maliciosas. Transposto para 0 contexto brasileiro, esse formato se nacionalizou, adquirindo características próprias de nosso ambiente cultural. Encontrado terreno fértil, 0 gênero erótico se aclimata e se desenvolve, tomando expressão própria [...] de forma que, rapidamente, a produção local não tem mais a ver com o modelo italiano. [...] Como na chanchada, pode-se perceber a assimilação de formas tradicionais de entretenimento popular brasileiro, advindas do esquete de teatro de revista, dos espetáculos mambembes, do circo e, mesmo, do rádio - este já fazendo parte da cultura de massa. (ABREU, 2006, p. 143-144)

Abreu também observa que havia um meio cultural específico favorável ao surgimento desses filmes, construído pelo cinema brasileiro, sobretudo o carioca, ao longo dos anos 1960, com uma linhagem de comédias de costumes cujos temas variavam em torno dos encantos do sexo e das relações amorosas, como Toda donzela tem um pai que é uma fera (Roberto Farias, 1966), Todas as mulheres do mundo (Domingos de Oliveira, 1967) e Adultério à brasileira (Pedro Carlos Rovai, 1969).

Tratava-se de filmes leves, bem-sucedidos comercialmente e tolerados pela crítica, apontando para um veio de seguro no mercado.

A teórica feminista Ann Kaplan (1993, p. 23) tinha uma teoria para explicar a proliferação de filmes desse tipo no final dos 1960 e começo dos 1970 (justamente a época da chamada "liberação feminina"), e tal explicação se tornou, com o tempo, aceita de maneira quase unânime. Segundo Kaplan, os filmes proliferaram porque "[...] a maior hostilidade patriarcal é agora expressa na idéia de que todas as mulheres anseiam o tempo todo por sexo. Nessa idéia, a repulsa (do homem) nasce de ele ser forçado a reconhecer a vagina e, com isso, a diferença sexual. A reação masculina é querer 'dá-lo a ela', o mais dolorosamente possível e de preferência à força, primeiro para puni-la pelo tal (suposto) desejo, segundo para asseverar o controle sobre a sexualidade dela $\mathrm{e}$ finalmente provar a 'masculinidade' pela habilidade de dominar com o falo." 
0 sucesso de público desses filmes levou à produção de outros, menos sofisticados, que também se beneficiariam das leis de obrigatoriedade de exibição de filmes nacionais, ocupando as salas com um tipo de representação erótica e popular. Logo, essas "pornochanchadas" cariocas e paulistas passariam a ser a "marca" do cinema popular brasileiro da década de 1970 . Mas, ainda que 0 rótulo tenha se consagrado, muitos desses filmes se afastaram da comédia, fazendo o mesmo caminho que os filmes de sexploitation haviam feito cerca de uma década antes: partiriam para exibição de cenas de sexo simuladas em filmes divertidos para, em seguida, começarem a colocar as personagens femininas em situações cada vez mais violentas.

Tal ciclo de filmes acabou tendo vida longa no Brasil em função da conjuntura nacional. Afinal, a censura aos filmes estrangeiros de sexo explícito (que haviam sido liberados nos EUA desde 1972, mas só chegariam por aqui dez anos depois, quando substituiriam rapidamente a pornochanchada) deixou nosso mercado livre para desenvolver um cinema erótico que recorria a diversas estratégias do cinema de sexploitation. Os filmes de sexploitation brasileiros mostravam, inclusive, uma curiosa autoconsciência a respeito das discussões que circulavam na época acerca do cinema erótico, o que mostra que os cineastas não estavam alheios às críticas que recebiam, tanto da crítica conservadora quanto das feministas e dos intelectuais e artistas engajados na luta política do período.
Diversos filmes, por exemplo, ao representar a violência desmedida e inexplicável contra as mulheres, também problematizavam, à sua maneira, o tipo de representação dessa violência, colocando em pauta as interpretações mais comuns na época, como a que relacionava os filmes a fantasias de sexo e morte, aos dilemas de homens que tentavam dominar mulheres sexualmente livres, à impossibilidade da exibição do sexo explícito ou à preferência do público por cenas chocantes. São representantes dessa autoconsciência, entre outros, longas-metragens como Amadas e Violentadas (Jean Garret, 1976), que trazia 0 ator/produtor/diretor David Cardoso no papel de um escritor serial-killer que escreve sobre serial-killers, e $O$ estripador de mulheres (Juan Bajón, 1977), que tratava da exploração jornalística sensacionalista de um caso de assassinato serial. Em ambos, cenas sensacionais de assassinatos de belas mulheres vinham acompanhadas de diálogos reflexivos a respeito, num procedimento metalinguístico bastante evidente.

Auto-reflexivas ou não, entre as obras nacionais de sexploitation de horror, destacam-se os ghoulies brasileiros, nos quais personagens femininas ficavam a mercê de entidades sobrenaturais violentas, como Seduzidas pelo Demônio (Raffaelli Rossi, 1977), o Castelo das Taras (Julius Belvedere, 1982), O banquete de taras (Carlos Alberto de Almeida, 1982) e $A$ mulher, a serpente e a flor (J.B.Marreco, 1983), entre outros, e os roughies brasileiros que 
traziam crimes bizarros praticados por assassinos seriais do sexo masculino contra belas mulheres, como os já mencionados Amadas e Violentadas e $O$ Estripador de Mulheres, além de $O$ matador sexual (Tony Vieira, 1979), O Pasteleiro ${ }^{4}$ (David Cardoso, 1981) $O$ Violino ${ }^{5}$ (Cláudio Portioli, 1982), entre muitos outros.

Em todos esses filmes até agora mencionados, e também seus similares, nota-se que a posição das personagens femininas era a de indefesas e desejáveis vítimas a mercê de homens descontrolados que as viam como meros objetos de desejo sexual e sádico, expostas em cenas de nudez e sangue que, não raro, apelavam ao mau gosto e à linguagem chula. Sem dúvida, tais filmes pareciam dar continuidade ao chauvinismo de seus antecessores mais bem-humorados, dos quais mantinham locações, elenco, modelo de produção, equipe técnica e público cativo.

\section{$3 \mathrm{~A}$ vingança das mulheres monstruosas}

Mas, curiosamente, no ambiente do sexploitation de horror brasileiro, nem todas as vítimas foram mulheres. Pelo contrário: com alguma frequência, em meio a ghoulies e roughies, elas foram os verdadeiros monstros das histórias que estrelaram, gerando um grupo significativo de obras nas quais o sexo feminino, de alguma forma, "deu o troco" nos abusos que sofria dos homens. Esses filmes colocavam personagens femininas em papéis quase sempre reservados a eles, como os de predadoras sexuais, dominadoras e mesmo assassinas do sexo oposto.

Fauzi Mansur foi um dos primeiros a explorar essas possibilidades ao dirigir a farsa Belas e corrompidas (1977), também conhecida como Asferas do sexo ou Sexta-feira as bruxas ficam nuas, escrita por Marcus Rey e fotografada por Cláudio Portioli. No filme, Maria Isabel de Lizandra interpretava Isabel, uma mulher rica, solteira e fascinada pela personalidade do famoso serial-killer Landru ${ }^{6}$, e que mata, com a ajuda de sua empregada corcunda, uma série de homens na sua mansão. Ao se apaixonar por um policial, porém, ela precisa se livrar de seu passado, e é levada a um julgamento no qual seduz todos os jurados, sendo absolvida e libertada.

0 filme foi execrado pelos críticos, em boa parte pelo que eles consideraram o desperdício de uma boa ideia: a mudança do papel típico da mulher na pornochanchada? . Mas Belas e Corrompidas era uma comédia e, nesse sentido, a inversão

Terceiro episódio do longa-metragem Aqui, tarados!.

Segundo episódio do longa-metragem Noite das taras 2.

Henri Desiré Landru (1869-1922) é o mais famoso serial-killer da história da França, tendo assassinado, por envenenamento, pelo menos 11 mulheres entre 1914 e 1918, e tendo sido condenado à morte e executado em 1921. Sua história deu origem a vários filmes, entre eles MONSIEUR VERDOUX (Charlie Chaplin, 1947) e LANDRU (Claude Chabrol, 1962). 
dos papéis fazia parte da piada. 0 mesmo não se deu com o primeiro filme do chinês naturalizado brasileiro, John Doo, Ninfas diabólicas (1977), co-escrito por Ody Fraga (então um roteirista quase onipresente nos filmes da Boca) e fotografado pelo cineasta e cinegrafista Ozualdo Candeias. Nesse filme, Sérgio Hingst interpretava o executivo Rodrigo, que dá carona a duas jovens estudantes, Úrsula e Circe (Aldine Muller e Patrícia Scalvi) e acaba se envolvendo com elas, não conseguindo, porém, impedir que Circe mate Úrsula por ciúmes. Ele foge de carro com Circe, mas Úrsula reaparece magicamente. Rodrigo se assusta, e seu o automóvel cai numa ribanceira, matando-0. Então, as duas moças saem do carro, recompostas, como duas jovens estudantes, para pedir mais uma carona a algum homem solitário na estrada.

0 filme é ainda hoje um dos mais lembrados da Boca do Lixo, embora não tenha sido comercializado posteriormente em VHS, e nem exibido na televisão. A partir dele, Doo ganharia a fama de cineasta competente e arrojado, construindo uma carreira meteórica ao lado de bons profissionais, e quase sempre realizando filmes com temas fantásticos, roteirizados por ele. Além de causar grande impressão aos realizadores da Boca, seu filme seria também um sucesso de bilheteria, o que 0 incentivaria a voltar ao tema das mulheres monstruosas mais vezes. Em 1980, Doo e Fraga reuniriam-se mais uma vez no curta-metragem $O$ gafanhoto, terceiro episódio do longa Pornô!, da produtora de David Cardoso, a Dacar, então uma das mais poderosas empresas da Boca. Em O gafanhoto, Zélia Diniz interpretava Diana, uma pianista cega que mora em uma mansão isolada no alto de uma montanha, e que só consegue enxergar através de misteriosos espelhos que se multiplicam pela casa. Ela vive com sua empregada (Liana Duval) e com o jovem Marcos (Arthur Roveder), amante que ela conseguira dominar e trancar em sua casa, transformando-0 em uma espécie de escravo sexual. Marcos tenta, de várias maneiras, libertar-se da situação, mas Diana continua a dominá-lo, pois controla suas ações através dos espelhos. Numa manhã, Marcos encontra um gafanhoto em seu quarto, e usa-0 para excitar Diana, sem que ela perceba. Quando ela descobre 0 fato, porém, excita-se ainda mais, ficando obcecada pelo animal, e fazendo com que Marcos, enciumado e chocado, decida, finalmente, partir. Para isso, ele começa a quebrar todos os espelhos da casa, ferindo magicamente Diana a cada estilhaço. Mas ela é mais forte do que ele, e consegue sobreviver aos cortes e matá-lo, reinando sozinha na casa em meio aos espelhos quebrados.

Ao som de Chopin e ao sabor de belos movimentos de câmera, O gafanhoto é possivelmente um dos filmes mais interessantes já realizados na Boca do Lixo, e, segundo o crítico Rubem Biáfora, pode ser uma adaptação livre do conto O Espelho ${ }^{8}$, de Gastão Cruls. 
Independentemente das fontes literárias não creditadas, o filme se apresenta como um conto fantástico doentio realizado com talento, fugindo claramente ao padrão em meio a uma produção muito pouco dada às variações estilísticas e temáticas.

Depois dele, Doo voltaria ao tema das mulheres monstruosas mais vezes. Em 1981, em coprodução com Cassiano Esteves, realizaria Ninfas insaciáveis, roteirizado em parceria com Waldir Kopesky e fotografado por Antonio Meliande, então um dos profissionais mais requisitados da Boca. 0 filme retomava - sobretudo no título - 0 tema das "ninfas", desta vez numa comunidade de pescadores atacada por bandidos e protegida pelas filhas de um pescador - que, na verdade, são ninfas enviadas por Iemanjá (Zilda Mayo, Alvamar Taddei, Tânia Gomide e Nádia Destro) para destruir os homens. No ano seguinte, Doo e Esteves uniram-se ao fotógrafo Cláudio Portiloi (de $O$ gafanhoto) para realizar Excitação diabólica, escrito por Doo e estrelado por Aldine Muller, Zaira Bueno e Wanda Kosmo. No filme, três motociclistas assediam e maltratam uma velha prostituta, que, dotada de poderes sobrenaturais, volta-se contra eles, surgindo diante de cada um como uma linda jovem que os leva à autodestruição.

Em 1982, Doo ainda participaria da produção independente Delírios eróticos - em mais uma pareceria com Waldir Kopezki e com 0 desconhecido Peter Ivan Joséf Racz - filme que, curiosamente, continha três curtas-metragens diferentes abordando o tema das mulheres monstruosas ou vingadoras. 0 segmento de Kopezki chamou-se Sussurros e gemidos, e foi estrelado por Fabio Vialonga e Rosângela Gomes, com roteiro de Doo. No curta, um homem observa 0 ato amoroso de um casal na chuva, e, depois, numa noite de tempestade, a mulher se oferece para ele como uma espécie de "ninfa da chuva". Ele aceita a sedução e, depois, acorda nu, na floresta, onde encontra, aterrado, vários corpos de homens assassinados e percebe, então, que também está ferido mortalmente, com uma cruz cravada no peito. Já o curta de Racz, Ressurreição, estrelado por Flavio Potho e Suzana Nicolas, trazia a história de um psiquiatra seduzido e levado à loucura por uma moça que acredita estar possuída pelo espírito da uma deusa indiana. Por fim, o episódio de Doo, mais distante do horror, estrelado por Lia Furlin e Arlindo Barreto, foi intitulado Amor por telepatia. A história se passa num ônibus, quando um rapaz e uma moça observam-se reciprocamente e imaginam seu futuro juntos. Mas, enquanto ele planeja o casamento dos dois, ela tem diversos devaneios sadomasoquistas que incluem a castração do rapaz.

Infelizmente, hoje, a maioria dos filmes de John Doo estão indisponíveis, sendo possível contar apenas com fontes secundárias (sinopses 
e matérias em revistas da época) para falarse sobre eles. Mas tratam-se, certamente, de exemplos bastante contundentes do interesse dos realizadores da Boca pelo assunto das "mulheres monstruosas" no começo dos anos 1980.

E ele não era o único. Ainda em 1982, seria a vez de Mario Vaz Filho trazer as mulheres assassinas em Noite infinita, primeiro episódio do longa Bonecas da noite (1982), realizado em parceria com Luiz Castelini. No segmento de Castelini, o filme trazia a figura mais "tradicional" do assassino de prostitutas $^{10}$. Mas, no segmento de Vaz Filho, temos Paula, bela mulher que leva homens para uma fazenda onde funciona um frigorífico, e, lá, mata-os para comercializar sua carne.

Seria, porém, o fotógrafo Antonio Meliande, então em seu quinto longa-metragem como diretor, que realizaria o mais engajado filme sobre vingança feminina na Boca do Lixo: Liliam, A Suja, escrito por ele e Rajá de Aragão, em 1981, para a produtora de Antonio Pólo Galante. No filme, Lia Furlin interpretava a personagem-título, uma bela moça de periferia que trabalha como secretária numa empresa do centro de São Paulo. Por não poder perder 0 emprego, já que precisa cuidar da mãe doente e paraplégica (Leonor Lambertini), ela se submete aos caprichos sexuais e ao chauvinismo do patrão
Daniel (Felipe Levy), que não a deixa em paz, submetendo-a, sob ameaças de demissão, a situações constrangedoras e humilhantes. Para esquecer sua vida difícil, frequenta, durante a noite, boates ricas, onde caça homens, fazendo sexo com eles, para depois matá-los, deixando sempre um bilhete escrito com batom: "Liliam, a Suja". A polícia, totalmente perdida, não tem a menor ideia de quem seja a assassina, imaginando tratar-se de alguma travesti. Apenas sua mãe desconfia que haja algo errado com a filha. Mas Liliam continua sua descida ao inferno e, depois de envenenar o patrão, acaba sendo morta, em casa, por uma bala perdida que estava reservada a um bandido terrível, um estuprador e assaltante que tivera 0 "corpo fechado" por um pai de santo. Morta no jardim, Liliam é encontrada por um policial, que vê, em sua bolsa, o bilhete com as palavras: "Liliam, $a$ Suja". Indiferente ao drama e ao corpo, ele vai embora, assim como o restante dos policiais, $\mathrm{e}$ sua mãe fica sozinha na casa, abandonada por todos e chorando o cadáver da filha.

0 texto de Rubem Biáfora, publicado na época do lançamento, sugeria que o filme poderia ter sido baseado em um longa-metragem holandês, mas não dá mais informações sobre isso. De qualquer forma, e mesmo reconhecendo os problemas do filme, o crítico também percebia que, pelo menos

A partir do final dos anos 1970 até 1983, foram feitos diversos filmes na Boca do Lixo abordando o tema dos serial killers de prostitutas. Pode haver várias explicações para isso, como a grande quantidade de personagens prostitutas nos filmes da Boca ou a recorrência do tema no cinema estrangeiro. Mas também é possível creditar esses filmes à influência da segunda prisão do assassino serial Francisco Costa Rocha (conhecido como Chico Picadinho), em 1978, após ter assassinado e esquartejado uma prostituta, num episódio que mobilizou toda a imprensa brasileira e teve grande repercussão popular. 
no contexto do cinema erótico brasileiro, o longa de Meliande poderia ter algo de novo a dizer:

[...] não vamos pensar numa mitológica Louise Brooks vagando expressionisticamente pelas ruas soturnas de Berlim [...] sob a batuta de Pabst em A CAIXA DE PANDORA [...] Mas não seria má matéria-prima esta ideia de uma moça traumatizada e perdida pela miséria [...], além de humilhada e assediada pelo patrão boçal durante 0 expediente do único emprego que conseguiu arranjar numa época de recessão. [...] Ao que parece, trata-se do fac-símile antecipado de um filme holandês da atual safra erótica que um dos financiadores behind teria visto por lá ou tomado conhecimento, via comentários ou publicações especializadas. [...] A verificar? (BIÁFORA, 1982).

Liliam, a suja, mais do que um filme de horror, parecia uma crítica ao desamparo ao qual Liliam e sua mãe estavam sujeitas - desamparo que começara no pai (que aleijara a própria mulher e abandonara a filha), passava pelo patrão, pelos homens da polícia e até por Deus, que preferira fechar o corpo de um criminoso do sexo masculino do que proteger a vida da jovem. A trilha sonora mantém esse mesmo tom, pois, em vez de explorar 0 suspense ou 0 susto, como seria natural esperar-se num filme ligado ao horror, traz melancolia e uma certa tristeza, reforçando o tom fúnebre. Outro aspecto curioso desse filme é a precariedade das armas usadas nos assassinatos, que são pequenas e pouco ameaçadoras navalhas ou giletes, o que sugere mais fortemente os poderes especiais e a força inexplicável da personagem. Tudo isso, aliado à representação de Liliam como uma mulher trabalhadora e oprimida pelos homens, torna 0 longa de Meliande um caso muito específico no conjunto de filmes de serial-killers da Boca do Lixo, indicando que havia, nesse período, uma consciência e um certo desejo de discutir-se abertamente (e, quem sabe, autocriticamente) 0 papel reservado às mulheres nos filmes eróticos brasileiros, questionando-se clichês básicos como o desejo de submissão das mulheres, sua fraqueza física e sua busca por ascensão social através do sexo.

\section{Transgressões e evoluções}

Ao observar-se esse conjunto de pornochanchadas paulistas estreladas por mulheres monstruosas, torna-se possível propor uma leitura mais diversificada do cinema erótico brasileiro do que aquela que o consagrou simplesmente como uma manifestação machista e alienada de nosso cinema popular. Pois, ainda que esses filmes centrados em mulheres "más" e poderosas reproduzam uma série de preconceitos e façam parte de uma indústria que se voltou a fórmulas narrativas que priorizavam o olhar masculino (tanto dentro quanto fora da tela), eles inegavelmente colocaram em pauta a condição feminina sob um viés autocrítico e até "revanchista". Isso sugere que o sexploitation brasileiro não apenas "evoluiu" da nudez em direção à violência explicita, mas também em direção à reflexão sobre a representação e sobre o próprio uso do corpo da mulher pelo cinema. 
Afinal, se, como observa Abreu,

[...] era senso comum que, de uma atriz de pornochanchadas, não se deveria exigir mais que a presença física, pois os recursos cinematográficos - movimentos de câmera, enquadramentos e montagem trabalhariam por ela [...], conduzindo o desenvolvimento dramático do filme [...] [e fazendo da] pornochanchada 0 exemplo mais acabado de um cinema como narrativa e câmera definidos a partir de um ponto de vista masculino. (ABREU, 2006, p. 172 e 181)

Por outro lado, também é preciso reconhecerse que, através desse processo de exploração do corpo feminino, os filmes trouxeram, para universo das representações populares, a chamada revolução sexual que estava em curso desde a década de 1960, com temas como a liberação feminista, o elogio do prazer, 0 relaxamento dos costumes etc., e podem ter servido como um interessante laboratório de questões que foram sendo amadurecidas ao longo da década de 1970 (ABREU, 2006, p. 165). Uma dessas questões, certamente, foi a violência contra a mulher, mas também, como se pode perceber, a violência da própria mulher acabou sendo levada em consideração, ainda que de maneira contraditória, apontando para vias mais complexas do que a mão única de um tipo específico de ideologia machista que estaria ligada à produção e ao consumo desses filmes.

Assim, o espaço podia estar aberto para 0 surgimento de filmes como Belas e corrompidas, Excitação diabólica, Liliam, a suja e outros em meio a produções que tratavam as mulheres de maneira mais submissa. Afinal, como observa Piedade (2002, p. 06), se grande parte da produção exploitation surge compensando seus baixos orçamentos com apelos explícitos aos instintos dos espectadores masculinos, muitas vezes esses apelos podem se tornar elementos transgressores, mesmo que se apresentem de forma contraditória. Observando-se esses filmes de exploração com mais atenção, não é raro que se encontrem rasgos de conservadorismo ou preconceito ao lado de momentos perturbadores da ordem (social, sexual, política, estética...) vigente. Com isso, apesar da péssima fama, esses filmes oferecem um panorama interessante sobre as preocupações e aspirações inconfessáveis das sociedades em que são produzidos, e também participam, muitas vezes, do debate sobre elas. Nesse sentido, olhar para a pornochanchada sob um viés mais localizado pode acabar por revelar processos culturais muito mais interessantes e conflituosos do cinema popular brasileiro do final dos anos 1970 do que a visão generalizante (e ainda a mais frequente em nossa historiografia) registrada em nossa memória cinematográfica.

\section{Referências bibliográficas}

ABREU, Nuno César de. Boca do lixo: cinema e classes populares. Campinas: UNICAMP, 2006. 224 p.

BIÁFORA, Rubem. Liliam - a suja. 0 Estado de São Paulo, São Paulo, 03 jan. 1982.

CANEPA, Laura Loguercio. Medo de quê? - uma História do Horror nos Filmes Brasileiros. 2008. Tese (Doutorado em Multimeios)- Instituto de Artes, Universidade de Estadual de Campinas, Campinas, 2008. 
KAPLAN, E. Ann. A mulher e o cinema: os dois lados da câmera. Rio de Janeiro: Rocco, 1993. 347 p.

PIEDADE, Lúcio F. dos Reis. A cultura do lixo: horror, sexo e exploração no cinema. 2002. 150 p. Dissertação (Mestrado em Multimeios)- Instituto de Artes,

Universidade Estadual de Campinas, Campinas, 2002.

SCHAEFFER, Erik. Bold! Daring! Shocking! True!

A History of expoitation films - 1910-1959. Dunhan:

Duke University Perss, 1999.

WILLIAMS, L. Film bodies: gender, genre, and excess.

In: R. STAM; T. MILLER (orgs.). Film and theory: an anthology. Oxford: Blackwell, 2000, p. 207-221. 


\section{The case of monster women in Brazilian sexploitation movies}

\section{Abstract}

This paper discusses a number of erotic horror movies in Brazil between the end of the 1970s and the beginning of the 1980s that were starred by monster women, reversing one of the basic structures of those movies, which was the representation of men always as stronger and more threatening than women. The objective is to demonstrate that the films had some discussion on the position of women in cinema and society, showing capacity for reflection and self-criticism that is not always considered in the analysis of that cinematography.

\section{Keywords}

Sexploitation movies. Brazilian pornochanchada. Horror. Monstrosity. Feminine gender.

\section{El caso de las mujeres monstruo en películas brasileñas de sexploitation}

\section{Resumen}

En este artículo se describe una serie de pornochanchadas de horror realizadas en Brasil entre el final de la década de 1970 y comienzos de 1980, que fueran protagonizados por mujeresmonstruo, cambiando una de las estructuras básicas de la pornochanchada, que trae la representación de los hombres siempre como más fuertes y amenazadores que las mujeres. El objetivo es demostrar que las películas eróticas realizadas en esta época generaron cierto debate sobre la posición de la mujer en el cine y la sociedad, mostrando capacidad de reflexión y auto-crítica que no siempre es considerada en el análisis de esa categoría de películas.

\section{Palabras clave}

Sexploitation movies. Pornochanchada brasileña. Horror. Monstruosidad. Género femenino. 


\section{Expediente}

A revista E-Compós é a publicação científica em formato eletrônico da Associação Nacional dos Programas de Pós-Graduação em Comunicação (Compós). Lançada em 2004, tem como principal finalidade difundir a produção acadêmica de pesquisadores da área de Comunicação, inseridos em instituições do Brasil e do exterior.
E-COMPÓS I www.e-compos.org.br I E-ISSN 1808-2599

Revista da Associação Nacional dos Programas de Pós-Graduação em Comunicação. Brasília, v.12, n.1, jan./abr. 2009.

A identificação das edições, a partir de 2008 passa a ser volume anual com três números.

\section{CONSELHO EDITORIAL}

\section{Afonso Albuquerque}

Universidade Federal Fluminense, Brasil

Alberto Carlos Augusto Klein

Universidade Estadual de Londrina, Brasi

Alex Fernando Teixeira Primo

Universidade Federal do Rio Grande do Sul, Brasil

\section{Alfredo Vizeu}

Universidade Federal de Pernambuco, Brasil

Ana Carolina Damboriarena Escosteguy

Pontifícia Universidade Católica do Rio Grande do Sul, Bras

Ana Silvia Lopes Davi Médola

Universidade Estadual Paulista, Brasil

André Luiz Martins Lemos

Universidade Federal da Bahia, Brasil

Ângela Freire Prysthon

Universidade Federal de Pernambuco, Brasil

Antônio Fausto Neto

Universidade do Vale do Rio dos Sinos, Brasil

Antonio Carlos Hohlfeldt

Pontifícia Universidade Católica do Rio Grande do Sul, Brasil

Arlindo Ribeiro Machado

Universidade de São Paulo, Brasil

César Geraldo Guimarães

Universidade Federal de Minas Gerais, Brasil

Cristiane Freitas Gutfreind

Pontifícia Universidade Católica do Rio Grande do Sul, Brasil

Denilson Lopes

Universidade Federal do Rio de Janeiro, Brasil

Eduardo Peñuela Cañizal

Universidade Paulista, Brasi

Erick Felinto de Oliveira

Universidade do Estado do Rio de Janeiro, Brasil

Francisco Menezes Martins

Universidade Tuiuti do Paraná, Brasil

Gelson Santana

Universidade Anhembi/Morumbi, Brasi

Hector Ospina

Universidad de Manizales, Colômbia

leda Tucherman

Universidade Federal do Rio de Janeiro, Brasil

Itania Maria Mota Gomes

Universidade Federal da Bahia, Brasil

Janice Caiafa

Universidade Federal do Rio de Janeiro, Brasil

Jeder Silveira Janotti Junior

Universidade Federal da Bahia, Brasil

\section{João Freire Filho}

Universidade Federal do Rio de Janeiro, Brasil

John DH Downing

University of Texas at Austin, Estados Unidos

José Luiz Aidar Prado

Pontifícia Universidade Católica de São Paulo, Brasil

José Luiz Warren Jardim Gomes Braga

Universidade do Vale do Rio dos Sinos, Brasil

Juremir Machado da Silva

Pontifícia Universidade Católica do Rio Grande do Sul, Brasil

Lorraine Leu

University of Bristol, Grã-Bretanha

Luiz Claudio Martino

Universidade de Brasília, Brasil

Maria Immacolata Vassallo de Lopes

Universidade de São Paulo, Brasil

Maria Lucia Santaella

Pontifícia Universidade Católica de São Paulo, Brasil

Mauro Pereira Porto

Tulane University, Estados Unidos

Muniz Sodre de Araujo Cabral

Universidade Federal do Rio de Janeiro, Brasil

Nilda Aparecida Jacks

Universidade Federal do Rio Grande do Sul, Brasil

Paulo Roberto Gibaldi Vaz

Universidade Federal do Rio de Janeiro, Brasil

Renato Cordeiro Gomes

Pontifícia Universidade Católica do Rio de Janeiro, Brasil

Ronaldo George Hela

Universidade do Estado do Rio de Janeiro, Brasil

Rosana de Lima Soares

Universidade de São Paulo, Brasil

Rossana Reguillo

Instituto Tecnológico y de Estudios Superiores do Occidente, México

Rousiley Celi Moreira Maia

Universidade Federal de Minas Gerais, Brasil

Sebastião Carlos de Morais Squirra

Universidade Metodista de São Paulo, Brasi

Simone Maria Andrade Pereira de Sá

Universidade Federal Fluminense, Brasil

Suzete Venturelli

Universidade de Brasília, Brasil

Valério Cruz Brittos

Universidade do Vale do Rio dos Sinos, Brasil

Veneza Mayora Ronsini

Universidade Federal de Santa Maria, Brasil

Vera Regina Veiga França

Universidade Federal de Minas Gerais, Brasil
COMISSÃO EDITORIAL

Ana Gruszynski I Universidade Federal do Rio Grande do Sul, Brasil

Rose Melo Rocha I Escola Superior de Propaganda e Marketing, Brasil

CONSULTORES AD HOC

Alberto Schneider I Visitante Tokyo University

Alexandre Rocha da Silva I Universidade Federal do Rio Grande do Sul, Brasil

Fernanda Bruno I Universidade Federal do Rio de Janeiro, Brasil

Ida Stumpf I Universidade Federal do Rio Grande do Sul, Brasil

Kati Caetano I Universidade Tuiuti do Paraná, Brasil

Laura Cánepa I Universidade Anhembi Morumbi, Brasi

Malena Contrera I Universidade Paulista, Brasil

Sandra Gonçalves I Universidade Federal do Rio Grande do Sul, Brasil

Vicente Gosciola I Universidade Anhembi Morumbi, Brasil

REVISÃO DE TEXTO E TRADUÇÃO I Everton Cardoso

EDITORAÇ̃̃o ELETRÔNICA I Raquel Castedo
COMPós I www.compos.org.br

Associação Nacional dos Programas de Pós-Graduação em Comunicação

Presidente

Erick Felinto de Oliveira

Universidade do Estado do Rio de Janeiro, Brasil erickfelinto@uol.com.br

Vice-presidente

Ana Silvia Lopes Davi Médola

Universidade Estadual Paulista, Brasil

asilvia@faac.unesp.br

Secretária-Geral

Denize Correa Araújo

Universidade Tuiuti do Paraná, Brasil

denizearaujo@hotmail.com 